Ambiente \& Água - An Interdisciplinary Journal of Applied Science
ISSN 1980-993X - doi:10.4136/1980-993X
www.ambi-agua.net
E-mail: ambi.agua@gmail.com

\title{
Desempenho de um reator Fenton em escala industrial aplicado à remoção de fenóis em uma planta de recuperação de resíduos da indústria de papel e celulose
}

\author{
doi:10.4136/ambi-agua.1638
}

Received: 30 Apr. 2015; Accepted: 21 Aug 2015

\author{
Everton Skoronski $^{1^{*}}$; Adilvo Ferrari ${ }^{2}$; Mylena Fernandes ${ }^{3}$; Cyntia Ely ${ }^{1}$; \\ Jair Juarez João ${ }^{4}$ \\ ${ }^{1}$ Universidade do Estado de Santa Catarina (UDESC), Lages, SC, Brasil \\ Departamento de Engenharia Ambiental \\ ${ }^{2}$ Serviço Nacional de Aprendizagem Industrial (SENAI), Blumenau, SC, Brasil \\ Departamento de Gerenciamento de águas e efluentes \\ ${ }^{3}$ Centro Universitário Unifacvest, Lages, S C, Brasil \\ Departamento de Engenharia Química \\ ${ }^{4}$ Universidade do Sul de Santa Catarina (UNISUL), Tubarão, SC, Brasil \\ Departamento de Engenharia Química \\ *Autor correspondente: e-mail: skoronski@cav.udesc.br, \\ adilvo.ferrari@mwv.com, mylena.fernandes@gmail.com, \\ cyntiaely_10@hotmail.com,jair.joao@unisul.br
}

\section{RESUMO}

Este trabalho descreve o desempenho de um reator Fenton em grande escala usado para remoção de fenol em uma planta de valorização dos resíduos da indústria de papel e celulose. O efluente consiste em óleo vegetal e fenol. A estação de tratamento objetiva tratar $4 \mathrm{~m}^{3} \mathrm{~h}^{-1} \mathrm{e}$ é constituída por um pré-tratamento para remoção de óleo, reator Fenton, Flotador de Ar Dissolvido - FAD e uma lagoa de aeração. Para a avaliação da estação de tratamento foram comparadas análises próprias do efluente com análises feitas em laboratório certificado. A eficiência global de remoção de fenol é maior do que 99,7\%. Foi demonstrado que a combinação do processo de oxidação avançada com o biológico constitui-se em um sistema de tratamentos interessante a fim de remover contaminantes recalcitrantes.

Palavras-chave: efluente, processo oxidativo avançado, reator em larga escala, tall oil.

\section{Performance of a Fenton reactor on an industrial scale applied to the removal of phenols in a waste recovery plant from the pulp and paper industry}

\begin{abstract}
This paper describes the performance of a Fenton reactor on an industrial scale applied to the removal of phenols in a waste recovery plant from the pulp and paper industry. The effluent consists of vegetal oil and phenol. The treatment plant is designed to treat $4 \mathrm{~m}^{3} \mathrm{~h}^{-1}$ and consists of a pre-treatment for oil removal, a Fenton reactor and an extended aeration tank. Internal and external analyses of the effluent were performed in order to evaluate the
\end{abstract}


treatment plant. The overall efficiency of phenol removal was higher than $99.7 \%$. It was demonstrated that the combination of biological and advanced oxidative process is a promising method of removing recalcitrant contaminants.

Keywords: advanced oxidative process, effluent, full scale reactor, tall oil.

\section{INTRODUÇÃO}

Os compostos fenólicos estão presentes em diversos efluentes de processos industriais tais como petroquímica, papel e celulose, farmacêutica, indústria têxtil, plástico, resinas e de fabricação de pesticidas, apresentando uma toxicidade bastante elevada. Os diversos processos biológicos aplicados para a remediação de compostos fenólicos apresentam baixa eficiência em concentrações acima de $100 \mathrm{mg} \mathrm{L}^{-1}$ devido a elevada toxicidade conferida por esses compostos aos microrganismos (Whiteley e Lee, 2006). Assim, processos de separação como a destilação, extração líquido-líquido com diferentes solventes, adsorção sobre carvões ativados e polímeros e adsorventes inorgânicos, pervaporação de membrana e membrana de extração em solvente, têm sido discutidas (Skoronski, 2010). Por outro lado, tecnologias de destruição, como os processos oxidativos avançados merecem destaque. Nos últimos anos, os processos oxidativos avançados vêm recebendo destaque com relação a sua aplicação no tratamento de efluentes, devido a sua alta eficiência na degradação de inúmeros compostos orgânicos e custo operacional baixo (Anotai et al., 2010). A grande vantagem destes processos, em relação aos processos convencionais de tratamento de efluentes está relacionada à sua elevada eficiência em oxidar compostos orgânicos complexos por ação do radical hidroxila $(\mathrm{OH} \cdot)$ transformando esses compostos em moléculas simples, mais facilmente biodegradáveis, ou até mesmo promovendo a total mineralização de toda a matéria orgânica presente no efluente (Namkung et al., 2008).

Dentre as principais modalidades utilizadas em processos de oxidação avançada destacam-se: processo Fenton $\left(\mathrm{H}_{2} \mathrm{O}_{2}\right.$ e íons $\left.\mathrm{Fe}^{2+}\right)$ ou foto-Fenton (quando se acrescenta luz ultravioleta ao meio), ozônio $\left(\mathrm{O}_{3}\right)$, peróxido de hidrogênio $\left(\mathrm{H}_{2} \mathrm{O}_{2}\right)$ e radiação ultravioleta, dióxido de titânio $\left(\mathrm{TiO}_{2}\right)$ e luz UV ou diferentes combinações dos processos citados anteriormente (Espulgas et al., 2002). O processo Fenton, que é o escopo deste trabalho, utiliza peróxido de hidrogênio e íons ferrosos, normalmente provenientes de sulfato ferroso como percursores do radical hidroxila ( $\mathrm{OH} \cdot)$, conforme Equação 1 (Neyens e Baeyens, 2003).

$\mathrm{O}$ pH utilizado no processo situa-se na faixa de 2,5 a 4,0 em função da solubilidade dos íons ferrosos e a possibilidade de formação de complexos não reativos entre a água e os íons ferrosos em pH baixo. Após a reação, o pH é ajustado e os íons ferrosos que foram transformados em íons férricos na reação são removidos do efluente por precipitação quando o pH do meio é ajustado para o descarte do efluente ou para a destinação do mesmo para etapas posteriores.

$$
\mathrm{H}_{2} \mathrm{O}_{2}+\mathrm{Fe}^{2+} \stackrel{\mathrm{H}^{+}}{\longrightarrow} \mathrm{OH}^{-}+\mathrm{OH}^{\bullet}+\mathrm{Fe}^{3+}
$$

O processo Fenton tem sido aplicado na remoção de compostos fenólicos em águas e efluentes (Pera-Titus et al., 2004). Vários estudos vêm sendo desenvolvidos recentemente, de forma a melhorar o desempenho do processo Fenton por meio da associação com energia elétrica, luz, magnetismo, aplicação de nanopartículas, ultrassom e o uso de reatores de leito fixos rotativos (Babuponnusami e Muthukumar, 2014). Mesmo diante destes novos estudos e embora o processo Fenton convencional esteja bem descrito na literatura e conte com um grande número de dados experimentais disponíveis sobre este processo, existe pouco ou nenhum trabalho que relate a aplicação desta metodologia em escala industrial e que 
comprove a sua viabilidade de implantação em larga escala. Em adicional, a maior parte dos trabalhos relata o uso de soluções sintéticas contendo água e fenol em solução. Os efluentes industriais são formados por matrizes mais complexas onde além do fenol, outros compostos estão presentes e apresentam potencial para diminuir a eficiência do processo comparado à sua aplicação em soluções aquosas. Os principais fatores estão relacionados ao consumo paralelo de peróxido de hidrogênio ou do radical hidroxila e também a complexação indesejada de íons ferrosos (Chamarro et al., 2001). Neste sentido, diversas ações relacionadas à aplicação de processo Fenton na remoção de fenol em efluentes industriais podem ser encorajadas ou um estudo de viabilidade pode ser considerado quando são relatadas experiências com processos conduzidos em escala maior que a laboratorial e também com efluentes coletados em campo.

A planta industrial onde está instalada a estação de tratamento de efluentes em estudo destina-se a extração de compostos químicos de interesse a partir de um resíduo da indústria de papel e celulose conhecido como Tall Oil Bruto. Este resíduo é um subproduto do processo de fabricação de celulose de fibra longa, composto de ácidos graxos e ácidos resinosos, resultantes da extração de lignina e hemicelulose da madeira durante a digestão da mesma com vapor em meio alcalino (Johansson, 1982). Na unidade industrial em questão, o Tall Oil passa por um processo de acidificação com $\mathrm{H}_{2} \mathrm{SO}_{4}$, sendo em seguida fracionado em colunas de destilação para a obtenção de compostos químicos de interesse comercial para os mercados de borracha, lubrificante, adesivo e alimentício. Antes de alimentar as colunas de destilação, ocorre um pré-aquecimento do Tall Oil que tem como objetivo remover a sua umidade. Consequentemente, durante este aquecimento, são carreados através do sistema de vácuo ácidos graxos leves e compostos fenólicos, onde juntamente com o condensado da caldeira, formam a principal fonte geradora de efluente. Este processo de valorização de resíduos da indústria de papel e celulose compõem um número cada vez maior de alternativas de processos que devem ser considerados para a implementação de biorefinaria (Bajpai, 2013).

A composição do efluente gerado apresenta majoritariamente água e óleo. Este último apresenta-se em concentração de 50 a $400 \mathrm{mg} \mathrm{L}^{-1}$ e é constituído de ácidos graxos leves de origem vegetal contendo compostos fenólicos. A concentração de fenóis no efluente é variável e apresenta-se na faixa de 250 a $400 \mathrm{mg} \mathrm{L}^{-1}$. Esta concentração está acima dos limites ambientais exigidos tanto pelo órgão estadual de Santa Catarina quando pelo órgão nacional. Em nível estadual, a Fundação de Meio Ambiente de Santa Catarina (FATMA) determina pela Lei 14.675 de 2009 que a concentração de fenol em efluentes industriais não deve exceder 0,2 $\mathrm{mg} \mathrm{L}^{-1}$ (Santa Catarina, 2009). Este limite é mais baixo que o definido pelo Conselho Nacional de Meio Ambiente (CONAMA) que por meio da Resolução 430 de 2011 estabelece o limite de 0,5 mg L $\mathrm{m}^{-1}$ para fenóis (Conama, 2011). Uma vez que a FATMA é responsável pela expedição das licenças ambientais de operação (LAO) no estado de Santa Catarina, a empresa deve seguir os limites ambientais impostos pela Lei 14.675 de 2009 e, portanto, deve atender ao limite ambiental mais restritivo apresentado anteriormente.

Diante deste contexto, o objetivo deste trabalho é apresentar os dados referentes à experiência de uma empresa de valorização de resíduos da indústria de papel e celulose. Esta empresa gera efluente com elevada concentração de fenol e aplica o processo Fenton na remoção deste contaminante como complemento aos processos tradicionais de tratamento de efluentes que não apresentam capacidade de adequar o efluente de saída aos padrões ambientais. 


\section{MATERIAL E MÉTODOS}

\subsection{Caracterização da estação de tratamento de efluentes (ETE) em estudo}

A ETE em estudo opera apenas 20 dias por mês, o tempo total de residência do efluente é de aproximadamente 137 horas (5,7 dias). A Figura 1 apresenta um fluxograma contendo as etapas envolvidas na ETE.

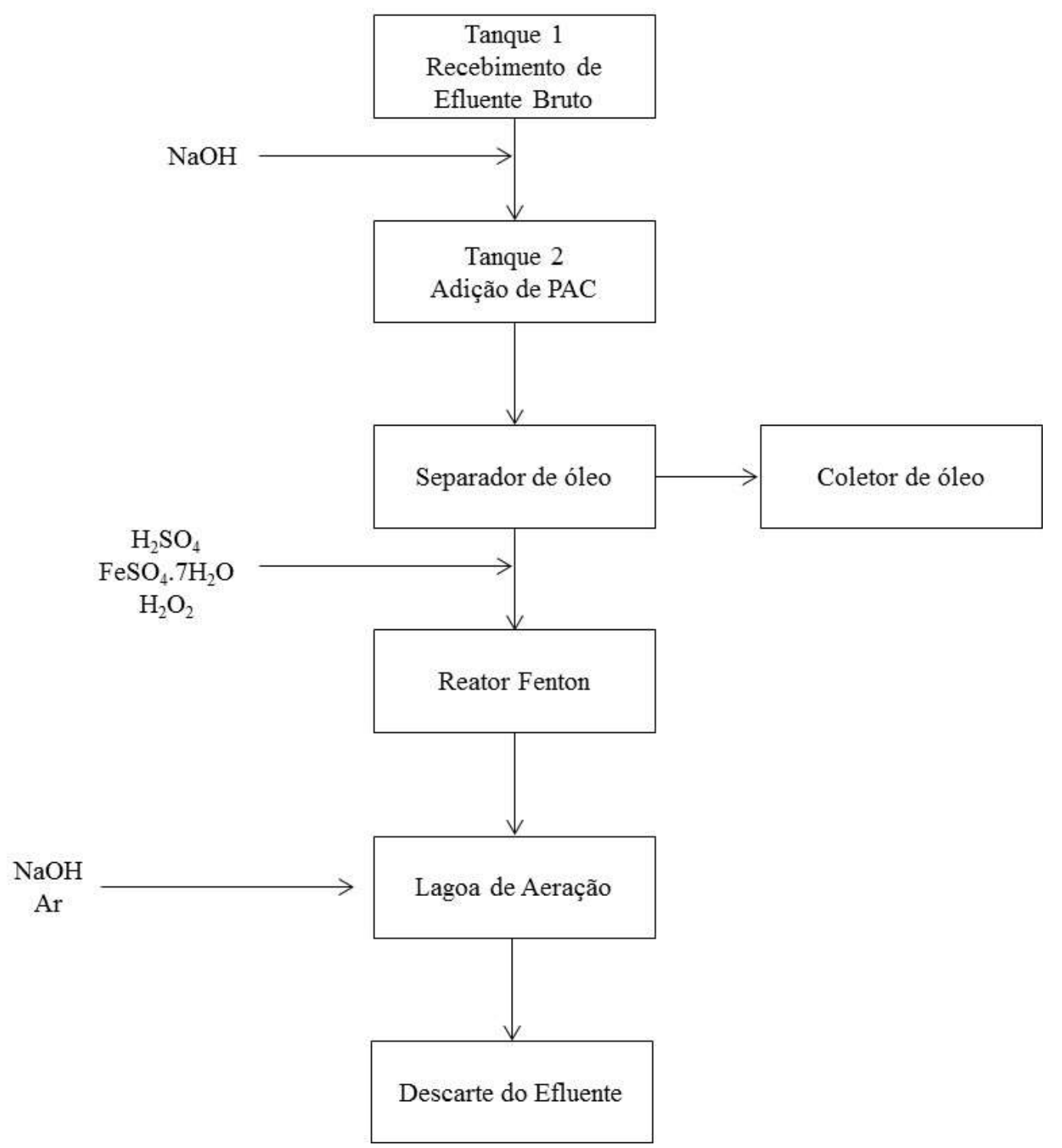

Figura 1. Fluxograma da estação de tratamento de efluentes.

$\mathrm{O}$ efluente gerado é recebido em tanques que equalizam o efluente em termos de composição e vazão para ser destinado às próximas etapas. Na sequência, o efluente recebe poli(cloreto de alumínio) (PAC - Praestol k2004) e hidróxido de sódio para ajustar o pH para 4,5 e em seguida passar por um tanque de separação de água e óleo (SAO), permitindo a remoção do material graxo suspenso. Logo após, é encaminhado para o reator onde ocorre o processo Fenton. Nesta etapa o pH do efluente de alimentação do reator Fenton é ajustado com ácido sulfúrico comercial para a faixa de $\mathrm{pH} 3,0$ a 3,5. A vazão de alimentação é constante e igual a $4,0 \mathrm{~m}^{3} \mathrm{~h}^{-1}$. O efluente recebe peróxido de hidrogênio 50\% (Hyprox 500) e sulfato ferroso heptahidratado $20 \%$ (Boreto \& Cardoso Ltda), que são misturados hidraulicamente na linha de recalque. O tempo de detenção hidráulico (TDH) é de 7,5 horas e 
o volume do reator é de $30 \mathrm{~m}^{3}$. Este reator consiste em um tanque com escoamento pistonado. O efluente de saída do reator Fenton recebe hidróxido de sódio com o objetivo de corrigir seu pH para valores acima de 6,0. Em seguida, o mesmo é encaminhado para uma lagoa de aeração (reator biológico) que possui como principal característica operar com um maior tempo de detenção hidráulico e com carga orgânica específica mais baixa, favorecendo o tratamento biológico de compostos com baixa biodegradabilidade. A carga orgânica específica média desta lagoa é de $0,04 \mathrm{KgDBO}_{5} \mathrm{KgSSV}^{-1} \mathrm{dia}^{-1}$. Os íons férricos gerados no reator Fenton são precipitados na lagoa de aeração e são eliminados do sistema juntamente com o lodo biológico em excesso, que é descartado da lagoa após limpezas periódicas, sendo o lodo enviado a aterro industrial.

\subsection{Monitoramento da eficiência da ETE}

A ETE é monitorada mensalmente por um laboratório externo, com o objetivo de avaliar as variáveis físico-químicas exigidas pelo órgão ambiental que expediu a licença ambiental de operação da empresa, listados na Tabela 1. Neste trabalho será apresentado o resultado do monitoramento realizado ao longo de um ano.

Além disto, é realizado também um controle interno com frequência diária, com o objetivo de corrigir problemas na ETE quando esta não atinge aos limites ambientais impostos no programa de monitoramento da empresa. Os parâmetros acompanhados pelo monitoramento interno são apresentados na Tabela 1. Neste trabalho será dado o enfoque para o parâmetro fenol e serão apresentados apenas os dados referentes ao monitoramento externo para os diversos parâmetros. A Tabela 2 apresenta os locais da ETE onde cada parâmetro é monitorado. Serão apresentados os resultados referentes ao monitoramento realizado ao longo de 191 dias.

Tabela 1. Parâmetros físico-químicos empregados para a avaliação interna e externa do desempenho da estação de tratamento de efluentes.

\begin{tabular}{ll}
\hline \multicolumn{1}{c}{ Local de Análise } & \multicolumn{1}{c}{ Parâmetros } \\
\hline Interno (Laboratório Próprio da Empresa) & $\mathrm{pH}$ \\
& Fenóis \\
& Demanda Química de Oxigênio \\
& Óleos Vegetais e Gorduras Animais \\
\hline & $\mathrm{pH}$ \\
Externo (Laboratório Contratado Com & Demanda Bioquímica de Oxigênio \\
Acreditação e Certificação NBR 17.025) & Demanda Química de Oxigênio \\
& Fenóis \\
& Nitrogênio Total \\
& Óleos Vegetais e Gorduras Animais \\
& Sólidos Sedimentáveis \\
& Sólidos Suspensos Totais \\
& Temperatura da Amostra \\
\hline
\end{tabular}

As análises físico-químicas são realizadas com base em metodologias recomendadas na literatura. 


\section{RESULTADOS E DISCUSSÃO}

\subsection{Desempenho da ETE na remoção de fenol}

A Figura 2 apresenta o desempenho do reator Fenton, da lagoa de aeração e da ETE na remoção de fenol, sendo os resultados apresentados em termos de concentração e realizados pelo laboratório interno da empresa.

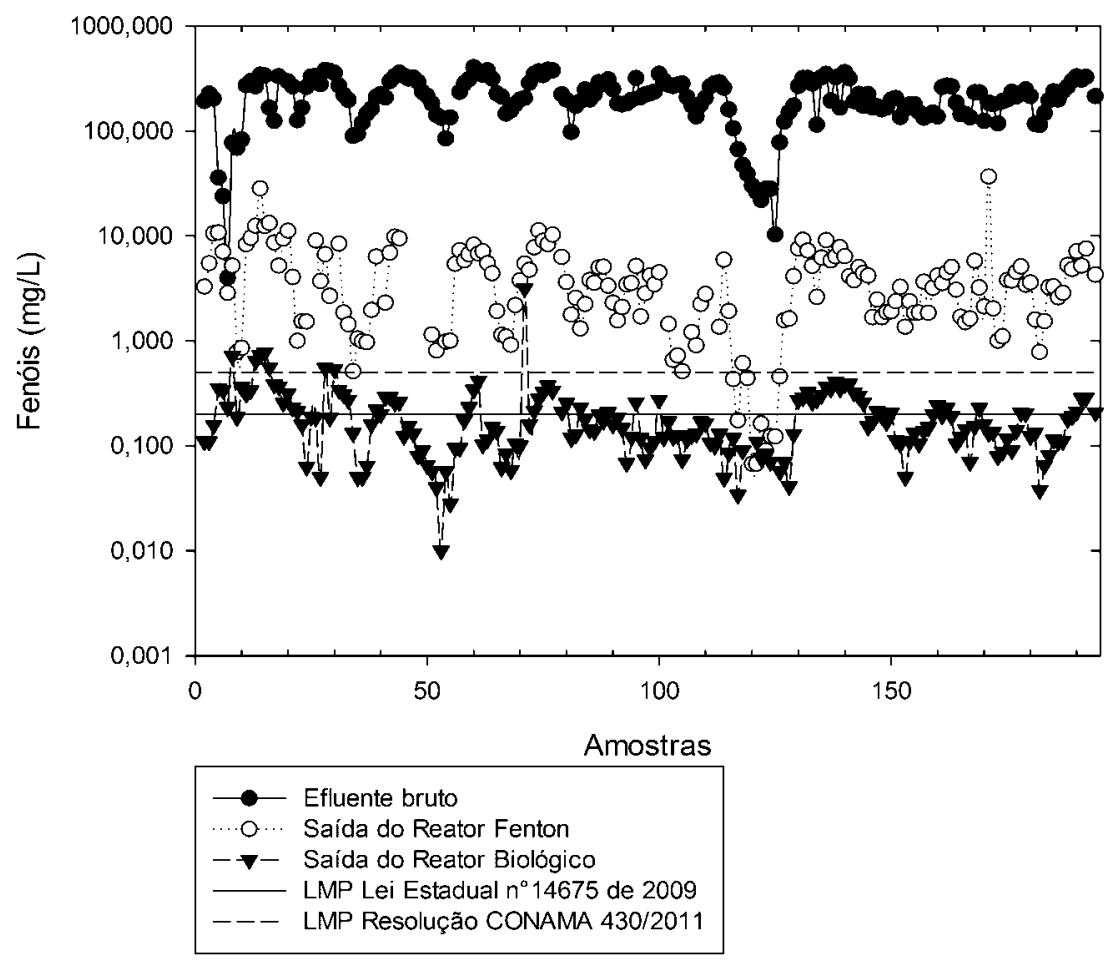

Figura 2. Desempenho da estação de tratamento de efluentes na remoção de fenol, apresentando a concentração de entrada e saída do reator Fenton, e saída da lagoa de aeração (efluente de descarte). São apresentados os limites ambientais para fenóis, exigidos pelo Estado de Santa Catarina $\left(0,2 \mathrm{mg} \mathrm{L}^{-1}\right)$ e Nacional $\left(0,5 \mathrm{mg} \mathrm{L}^{-1}\right)$.

Os resultados apontam que a concentração de entrada no reator apresenta um valor médio de $215,14 \mathrm{mg} \mathrm{L}^{-1}$ e varia entre 4,0 e 403,5 $\mathrm{mg} \mathrm{L}^{-1}$ (Tabela 2). Esta concentração inviabilizaria o tratamento biológico de efluentes e desta forma a aplicação do processo oxidativo avançado é justificável (Whiteley e Lee, 2006). No entanto, a Figura 2 demonstra que o reator Fenton não apresentou desempenho suficiente para atender aos limites ambientais exigidos pela legislação vigente, durante todo o período de monitoramento. A saída do reator Fenton apresenta uma concentração média de $2,43 \mathrm{mg} \mathrm{L}^{-1}$, variando entre 0,10 e $21,0 \mathrm{mg} \mathrm{L}^{1}$. Estes valores situam-se acima dos limites ambientais citados anteriormente. Apesar disto, estas concentrações são suficientemente baixas para serem aplicadas em um reator biológico, sem provocar efeitos inibitórios para o consórcio microbiano ali desenvolvido. Esta combinação de processos oxidativos avançados com reatores biológicos é relatada na literatura e apresentam-se como uma interessante opção sob o ponto de vista econômico (Marco et al., 1997). O desempenho do reator biológico complementa o tratamento em termos de remoção de fenol e apresenta uma concentração de saída média igual a $0,21 \mathrm{mg} \mathrm{L}^{-1}$, com concentração mínima abaixo do limite de quantifícação do método (Tabela 1) e máximo igual a $3,2 \mathrm{mg} \mathrm{L}^{-1}$. Em um universo de 191 amostras o limite de $0,2 \mathrm{mg} \mathrm{L}^{-1}$ exigido pela FATMA foi superado 
em 63 amostras e em apenas oito amostras o limite de $0,5 \mathrm{mg} \mathrm{L}^{-1}$ exigido pelo CONAMA foi ultrapassado.

A Figura 3 apresenta a eficiência de remoção de fenol na ETE e nos reatores Fenton e de aeração prolongada.

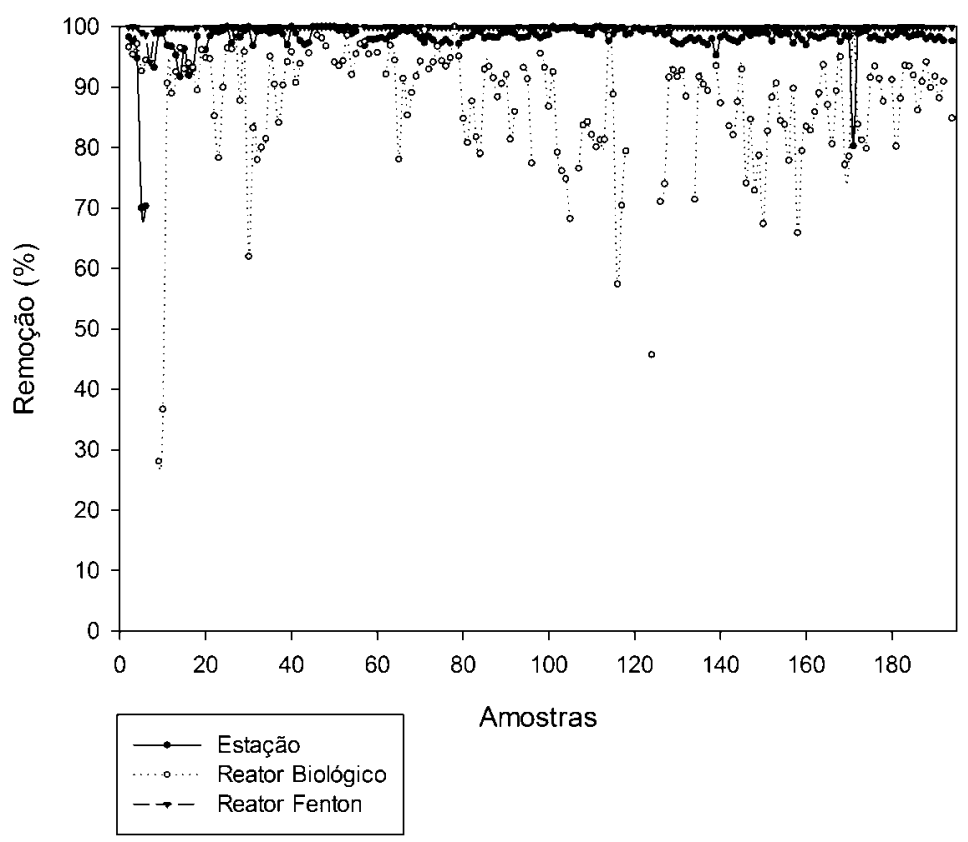

Figura 3. Eficiência de remoção de fenol no reator Fenton, no sistema de lodos ativados e da ETE.

Pode-se observar que a eficiência de remoção de fenol no reator Fenton atinge valores acima de 91,0\% durante o período de monitoramento, apresentando uma eficiência média de 98,4\%. Esta remoção de fenol é fundamental para que o reator biológico opere com sua eficiência média de $87,9 \%$. A eficiência global da ETE é em média 99,9\%, variando entre 99,7 e $100,0 \%$. Estes valores foram obtidos para uma concentração de $\mathrm{H}_{2} \mathrm{O}_{2}$ no efluente variável, de forma que seja mantida uma relação de $7 \mathrm{Kg}$ de $\mathrm{H}_{2} \mathrm{O}_{2}$ por $\mathrm{Kg}$ de fenol aplicado e relação $\mathrm{H}_{2} \mathrm{O}_{2}$ :Fe igual a 6:1, com tempo de detenção hidráulico de 7,5 horas. A US peroxide recomenda uma dosagem de $5 \mathrm{Kg}$ de $\mathrm{H}_{2} \mathrm{O}_{2}$ para tratar $1 \mathrm{Kg}$ de fenol (US Peroxide, 2009). Cabe salientar que na ETE o efluente considerado neste estudo apresenta uma matriz complexa, com a presença de várias substâncias orgânicas e, portanto, além do fenol, outras espécies são oxidadas, o que justifica o consumo acima do valor recomendado. Este controle da concentração de peróxido de hidrogênio é fundamental para o processo oxidativo avançado em questão. Alguns estudos relatam que o excesso de peróxido de hidrogênio é prejudicial à eficiência do processo Fenton, uma vez que o peróxido de hidrogênio em excesso consome radicais hidroxila formados e, portanto, diminuem a eficiência do processo (Ruppert et al., 1993). No entanto, os valores de eficiência obtidos na ETE são comparáveis aos resultados obtidos em laboratório por diversos autores, considerando a aplicação do processo Fenton na remoção de fenol. Esplugas et al. (2002) estudaram a aplicação de diversos processos oxidativos avançados na remoção de fenol em solução aquosa, com concentração entre 95 e $100 \mathrm{mg} \mathrm{L}^{-1}$. Em seu estudo foi verificado que o processo Fenton apresenta a maior eficiência de remoção e as condições otimizadas do seu estudo envolveram $363,8 \mathrm{mg} \mathrm{L}^{-1}$ de $\mathrm{H}_{2} \mathrm{O}_{2}$ e uma relação $\mathrm{H}_{2} \mathrm{O}_{2}: \mathrm{Fe}$ igual a 120:1 com um tempo de reação igual a 9,0 minutos. Este reduzido tempo não é observado em todos os trabalhos. Ruppert et al. (1993) estudaram a oxidação de uma solução contendo $94 \mathrm{mg} \mathrm{L}^{-1}$ de fenol e aplicaram uma concentração de peróxido de hidrogênio igual a $340 \mathrm{mg} \mathrm{L}^{-1}$ e relação $\mathrm{H}_{2} \mathrm{O}_{2}$ : $\mathrm{Fe}$ de aproximadamente 25:1. Somente após 5 
horas de reação a fração de fenol não reagido foi próxima de zero. No trabalho de Kavitha e Palanivelu (2004), os autores avaliaram a relação $\mathrm{H}_{2} \mathrm{O}_{2}$ : Fe, na eficiência de remoção de fenol em solução aquosa com concentração de $200 \mathrm{mg} \mathrm{L}^{-1}$. Os autores atingiram eficiência máxima de remoção de 82,0\% após 120 minutos de reação, aplicando uma concentração de peróxido igual a $1020 \mathrm{mg} \mathrm{L}^{-1}$ e relação $\mathrm{H}_{2} \mathrm{O}_{2}: \mathrm{Fe}$ de aproximadamente 23:1. No mesmo estudo, os autores verificaram que a relação citada anteriormente é fundamental no desempenho da reação, sendo o aumento na concentração de íons ferrosos favorável à eficiência de remoção de fenol, sendo este efeito também favorecido pela aplicação de luz ultravioleta.

Pontes e Pinto (2011) estudaram a otimização do processo Fenton para a remoção de fenol, levando em conta aspectos econômicos e financeiros. A concentração de fenol considerada foi de $94 \mathrm{mg} \mathrm{L}^{-1}$ e para o tratamento a concentração de peróxido de hidrogênio otimizada foi de $215,56 \mathrm{mg} \mathrm{L}^{-1}$. Em condições otimizadas o TDH do processo foi aproximadamente 15 horas e a relação $\mathrm{H}_{2} \mathrm{O}_{2}$ :Fe foi igual a 41:1.

\subsubsection{Monitoramento da ETE pelo laboratório externo}

O monitoramento da ETE pelo laboratório externo é obrigatório e determinado pelo órgão ambiental que expediu a licença ambiental de operação. A Tabela 2 apresenta um resumo dos valores medidos ao longo de um ano de monitoramento, com frequência mensal de coleta.

Em termos de concentração de fenol, as amostras coletadas atenderam aos limites ambientais citados neste trabalho, apresentando concentração máxima de $0,10 \mathrm{mg} \mathrm{L}^{-1}$. Além do fenol, outros parâmetros de interesse que não são o foco de discussão neste trabalho, mas são igualmente importantes e têm monitoramento exigido pelo órgão ambiental responsável, são apresentados. Observa-se que os parâmetros analisados atendem aos requisitos ambientais estipulados pelo órgão ambiental, com exceção do nitrogênio total e dos sólidos sedimentáveis em algumas campanhas de monitoramento. Em média, o efluente tratado encontra-se dentro dos padrões de lançamento exigidos pela legislação federal e pela estadual.

Em termos de demanda bioquímica de oxigênio $\left(\mathrm{DBO}_{5}\right)$, a estação de tratamento apresenta uma redução média de $87,0 \%$ no reator Fenton. Esta eficiência está associada à oxidação dos compostos orgânicos presentes no efluente. Neste sentido, o consumo de compostos químicos (peróxido de hidrogênio e sulfato ferroso) não é destinado prioritariamente à oxidação de fenol, sendo consumidos na oxidação de compostos que poderiam ser oxidados por via biológica. No entanto, esta oxidação não seletiva é necessária, uma vez que o sistema biológico não apresentaria um desempenho adequado devido à elevada concentração de fenol no meio. Esta observação abre campo para estudos que sejam direcionados à oxidação de compostos de interesse, sendo a aplicação de enzimas oxidativas uma alternativa que vem sendo abordada atualmente (Whiteley e Lee, 2006).

Foi observado que durante as campanhas de coleta externa, a concentração de fenol encontrou-se em acordo com os limites ambientais. No entanto, ao longo do monitoramento interno algumas análises apresentaram valores fora dos padrões, o que mostra que a acompanhamento com menores períodos é fundamental para controlar problemas durante a operação do reator Fenton que podem ocorrer de forma aleatória em períodos onde não exista a coleta para fins de controle externo, com um intervalo de amostragem elevado. 
Tabela 2. Dados compilados dos parâmetros físico-químicos utilizados para avaliação do desempenho da ETE realizados pelo laboratório externo e limites máximos permitidos exigidos pelos órgãos ambientais estadual e nacional.

\begin{tabular}{|c|c|c|c|c|c|c|c|c|c|c|c|}
\hline \multirow{3}{*}{ Parâmetro } & \multicolumn{9}{|c|}{ Local de amostragem } & \multicolumn{2}{|c|}{ Limites Máximos Permitidos } \\
\hline & \multicolumn{3}{|c|}{ Efluente Bruto } & \multicolumn{3}{|c|}{ Saída do Reator Fenton } & \multicolumn{3}{|c|}{ Saída da Lagoa de aeração } & \multirow[t]{2}{*}{$\begin{array}{c}\text { Resolução CONAMA } \\
430 / 2011\end{array}$} & \multirow[t]{2}{*}{$\begin{array}{l}\text { Lei Estadual } \\
14.675 / 2009\end{array}$} \\
\hline & Mínimo & Média & Máximo & Mínimo & Média & Máximo & Mínimo & Média & Máximo & & \\
\hline $\mathrm{pH}$ & 2,10 & 2,80 & 3,6 & 5,7 & 6,55 & 7,30 & 7,2 & 7,6 & 8,1 & 5 e 9 & 6 e 9 \\
\hline Remoção $\mathrm{DBO}_{5}(\%)$ & - & - & - & 48,65 & 87,04 & 97,95 & 85,89 & 97,34 & 99,93 & 60 & 80 \\
\hline $\mathrm{DBO}_{5}\left(\mathrm{mg} \mathrm{L}^{-1}\right)$ & 148,00 & $7.998,9$ & $17.923,0$ & - & - & - & 7,2 & 141,6 & 240,0 & - & 60 \\
\hline DQO $\left(\mathrm{mg} \mathrm{L}^{-1}\right)$ & 392,00 & 19467,0 & 65950,0 & 373 & 2090,0 & 4000,0 & 227,0 & 658,6 & 1630,0 & - & - \\
\hline Fenóis $\left(\mathrm{mg} \mathrm{L}^{-1}\right)$ & 4,90 & 269 & 480 & 0,00 & & 7,00 & 0,00 & 0,08 & 0,10 & 0,5 & 0,2 \\
\hline Nitrogênio total (mg N L'1) & - & - & - & - & - & - & 0,9 & 7,6 & 39,4 & $20^{1}$ & 10 \\
\hline $\begin{array}{l}\text { Óleos vegetais e gorduras animais } \\
\left(\mathrm{mg} \mathrm{L}^{-1}\right)\end{array}$ & 30,00 & 904,73 & 3009,0 & 7,00 & 12,33 & 21,00 & 6,0 & 9,0 & 15,0 & 50 & 30 \\
\hline Sólidos sedimentáveis $\left(m L L^{-1}\right)$ & - & - & - & - & - & - & 0,3 & 0,6 & 1,5 & - & $<0,1$ \\
\hline Sólidos Suspensos Totais $\left(\mathrm{mg} \mathrm{L}^{-1}\right)$ & - & - & - & - & - & - & 17,0 & 250,4 & 445,0 & - & - \\
\hline Temperatura da amostra $\left({ }^{\circ} \mathrm{C}\right)$ & - & - & - & - & - & - & 13,0 & 23,4 & 30,0 & 40 & 40 \\
\hline
\end{tabular}

${ }^{\mathbf{1}} \mathrm{O}$ limite refere-se ao nitrogênio amoniacal total. 


\section{CONCLUSÃO}

Os resultados apresentados neste trabalho demonstraram que o processo Fenton apresenta eficiência média de $98,4 \%$ na remoção de fenóis em um efluente gerado no processo de valorização de resíduos da indústria de papel e celulose. Entretanto, mesmo com elevada eficiência, este processo não atinge os limites ambientais exigidos pela legislação vigente, sendo necessário o complemento com o processo biológico. Esta associação de processos se mostrou eficiente para a remoção de fenol. Este trabalho apresentou os resultados obtidos em uma estação de tratamento de efluentes em larga escala, aplicando um processo oxidativo avançado, colaborando com a demonstração da viabilidade de scale up dos estudos até então desenvolvidos.

\section{REFERENCIAS}

ANOTAI, J.; SU, C. C.; TSAI, Y. C.; LU, M. C. Effect of hydrogen peroxide on aniline oxidation by electro-Fenton and fluidized-bed Fenton processes. Journal of Hazardous Materials, v. 183, p. 888-893, 2010. http://dx.doi.org/10.1016/j.jhazmat.2010.07.112

BABUPONNUSAMI, A.; MUTHUKUMAR, K. A review on Fenton and improvements to the Fenton process for wastewater treatment. Journal of Environmental Chemical Engineering, v. 2, p. 557-572, 2014. http://dx.doi.org/10.1016/j.jece.2013.10.011

BAJPAI, P. Biorefinery in the Pulp and Paper Industry. London: Academic Press, 2013.

CONSELHO NACIONAL DE MEIO AMBIENTE CONAMA (Brasil). Resolução n 430 de 13 de maio de 2011. Brasília, 2011. Resolução n ${ }^{\circ} 430$ de 13 de maio de 2011. Dispõe sobre as condições e padrões de lançamento de efluentes, complementa e altera a Resolução n³57, de 17 de março de 2005, do Conselho Nacional do Meio Ambiente CONAMA. Diário Oficial [da] União, Brasília, 13 maio 2011.

CHAMARRO, E.; MARCO, A.; ESPLUGAS, S. Use of Fenton reagent to improve organic chemical biodegradability. Water Research, v. 35, p. 1047-1051, 2001. http://dx.doi.org/10.1016/S0043-1354(00)00342-0

ESPULGAS, S.; GIMÉNEZ, J.; CONTRERAS, S.; PASCUAL, E.; RODRÍGUEZ, M. Comparison of different advanced oxidation processes for phenol degradation. Water Research, v. 36, p. 1034-1042, 2002. http://dx.doi.org/10.1016/S0043-1354(01)003013

JOHANSSON, A. By-product recovery and valorization in the kraft industry: A review of current trends in the recovery and use of turpentine and tall oil derivatives. Biomass, $\mathrm{v}$. 2, p. 103-113, 1982. http://dx.doi.org/10.1016/0144-4565(82)90020-8

KAVITHA, V.; PALANIVELU, K. The role of ferrous ion in Fenton and photo-Fenton processes for the degradation of phenol. Chemosphere, v. 55, p. 1235-1243, 2004. http://dx.doi.org/10.1016/j.chemosphere.2003.12.022

MARCO, A.; ESPULGAS, S.; SAUM, G. How and why combine chemical and biological processes for wastewater treatment. Water Science and Technology, v. 35, p. 321-327, 1997. http://dx.doi.org/10.1016/S0273-1223(97)00041-3 
NAMKUNG, K. C.; BURGESS, A. E.; BREMNER, D. H.; STAINES, H. Advanced Fenton processing of aqueous phenol solutions: A continuous system study including sonication effects. Ultrasonics Sonochemistry, v. 15, p. 171-176, 2008. http://dx.doi.org/10.1016/j.ultsonch.2007.02.009

NEYENS, E.; BAEYENS, J. A review of classic Fenton's peroxidation as an advanced oxidation technique. Journal of Hazardous Materials, v. 98, p. 33-50, 2003. http://dx.doi.org/10.1016/S0304-3894(02)00282-0

PERA-TITUS, M.; GARCÍA-MOLINA, V.; BAÑOS, M.; GIMÉNEZA, J. M.; ESPLUGAS, S. Degradation of chlorophenols by means of advanced oxidation processes: a general review. Applied Catalysis B: Environmental, v. 47, p. 219-256, 2004. http://dx.doi.org/10.1016/j.apcatb.2003.09.010

PONTES, R. F. F.; PINTO, J. M. Optimal synthesis of Fenton reactor networks for phenol degradation. Chemical Engineering Research and Design, v. 89, p. 706-721, 2011. http://dx.doi.org/10.1016/j.cherd.2010.08.017

RUPPERT, G.; BAUER, R.; HEISLER, G.; NOVALIC, S. Mineralization of cyclic organic water contaminants by the photo-fenton reaction - influence of structure and substituents. Chemosphere, v. 27, p. 1339-1347, 1993. http://dx.doi.org/10.1016/00456535(93)90228-W

SANTA CATARINA. Lei $\mathbf{n}^{\circ} \mathbf{1 4 . 6 7 5}$ de 13 de abril de 2009. Institui o Código Estadual do Meio Ambiente e estabelece outras providências. Florianópolis, 13 abril 2009.

SKORONSKI, E. Aplicação de Lacases Imobilizadas em Quitosana na Bioconversão de Compostos Fenólicos em Reatores Batelada e Contínuo. 2010. 110f. Tese (Doutorado em Engenharia Química) - Universidade Federal de Santa Catarina, Florianópolis, 2010.

US PEROXIDE. Fentons Reagent General Chemistry Using $\mathrm{H}_{2} \mathrm{O}_{2}$. In: UNIVERSIDADE DE SÃO PAULO. Technologies, solutions for a clean environment. 2009. Disponível em: <http://www.h2o2.com/>. Acesso em: 14 de junho de 2015.

WHITELEY, C. G.; LEE, D. J. Enzyme technology and biological remediation. Enzyme and Microbial Technology, v. 38, p. 291-316, 2006.

http://dx.doi.org/10.1016/j.enzmictec.2005.10.010 